\title{
LEARNING BY EXPERIENCE ON THE INNOCENCE PROJECT IN LONDON: THE EMPLOYER/ EMPLOYEE ENVIRONMENT
}

\author{
Louise Hewitt, Lecturer, School of Law, University of Greenwich
}

\section{Introduction}

The Innocence Project London is a pro bono project dedicated to investigating wrongful convictions in the context of individuals who claim actual innocence i.e. they did not commit the crime for which they have been convicted. ${ }^{1}$ Law students undertake work on the cases of convicted individuals who have maintained their innocence but have exhausted the criminal appeals process. The only avenue available to these individuals is to make an application to the Criminal Cases Review Commission (CCRC), which was set up to investigate the cases of people who believe they have been wrongfully convicted. ${ }^{2}$ The CCRC has the power to refer a case back to the Court of Appeal but requires new evidence or a new legal argument not identified at the time of the trial, which might have changed the whole outcome of the trial had the jury had been given a chance to consider it.

Innocence projects were developed in the United States of America (USA) and they have now spread globally, to include the Netherlands, Japan and Canada as well as in the United Kingdom. As such, Innocence Projects which meet the necessary criteria can apply to become members of the Innocence Network, which is based in New York. At present the Innocence Project London is the only UK project that it a member of this network.

\footnotetext{
${ }^{1}$ The distinction between wrongful convictions and miscarriages of justice in the context of an innocence project is articulated in Michael Naughton, 'Wrongful Convictions and Innocence projects in the UK: Help, Hope and Education", (2006) Web Journal of Current Legal Issues. The term wrongful conviction has however, been used in the context of the conviction of an individual secured as a material legal error where the individual concerned may not be innocent. Actual innocence typically means that the individual did not commit the crime of which he has been convicted. The discussion over the use of actual innocence is not the focus of this paper.

${ }^{2}$ Criminal Cases Review Commission https://ccrc.gov.uk/about-us/what-we-do/
} 
Whilst the notion of innocence projects has been much debated in literature ${ }^{3}$ the purpose of this paper is to present the pedagogy of the Innocence Project London (hereinafter IPL) and the meaningful learning opportunity it provides to students. The pedagogy combines experiential learning with elements of work based learning to create an employer/ employee environment. Law students are 'employed' to work on the IPL where the employment process starts with a two-stage application. The clinical learning model on an innocence project is distinct from the traditional clinic approach, in that students start work at the end of a case rather than at the beginning. The problem-solving therefore is developed in the context of critical judgement based on what happened when the case was decided in court as opposed to how the case should be presented in court. The learning for the students has been significant.

\section{The IPL Pedagogy}

The pedagogy of any innocence project, by virtue of the nature of the work, is underpinned by the experiential learning model from clinical legal education, ${ }^{4}$ but it provides a very different learning process for the student. ${ }^{5}$ As distinct from the law clinic model which requires an understanding of what facts are presented as agreed or considered insignificant, ${ }^{6}$ cases accepted by the IPL have already been decided and appealed. Students are required to disentangle them through an extensive

\footnotetext{
${ }^{3}$ Some interesting perspectives can be found in: Margaret Raymond, The problem with innocence, (2001) 49 Clev.St.L.Rev. 449: Jan Stiglitz, Justin Brooks, \& Tara Shulman, (2002) “The Hurricane Meets the Paper Chase: Innocence Projects New Emerging Role in Clinical Legal Education", 38 CAL. W. L. REV. 413: Daniel S. Medwed, (2003) "Actual Innocents: Considerations in Selecting Cases for a New Innocence Project", 81 NEB. L. REV. 1097. For a UK perspective see Stephanie Roberts and Lynne Weathered, "Assisting the factually innocence: The contradictions and Compatibility of Innocence Projects and the Criminal Cases Review Commission", (2008) Oxford Journal of Legal Studies, pp 1-28 and Hannah Quirk, "Identifying miscarriages of justice: Why innocence in the UK is not the answer", (2007) 70 (5) MLR 759-777

${ }^{4}$ For a full outline of what Clinical Legal Education is see Richard J Wilson, "Training for Justice: The Global Research of Clinical Legal Education", Penn State International Law Review: 22 (3), Article 5 at Part I

${ }^{5}$ Keith A. Findley, "The Pedagogy of Innocence: Reflections on the Role of Innocence Projects in Clinical Legal Education", Clinical Law Review, (Fall 2006), 13, 1101at 1105

${ }^{6}$ Findley, "The Pedagogy of Innocence: Reflections on the Role of Innocence Projects in Clinical Legal Education"
} 
investigation of fact alongside research into substantive law, to understand how and why their client was convicted. The students work is supervised by both an academic and a practising lawyer. The former provides support and advice on learning the law, whilst the latter provides practical advice and experience on how a court would consider any new evidence or legal arguments. There are two ways a student can work on the IPL, as a volunteer case worker or by selecting it as a third-year optional course.

\subsection{Learning by experience}

Rather than being taught in a passive style through a dissemination of information from the lecturer to the student, learning on the IPL is as a result of direct involvement with the case. The cases on the IPL place emphasis on the importance of facts, the value of being detailed, but also of being sceptical. ${ }^{7}$ Employees/students approach the facts of a case in order to tell the story, and then examine the facts in order to determine what went wrong and what new evidence or new legal argument might be used to prove innocence. There is great value in this process, where the employee/student learn how to be thorough, learn how to keep going when one area of investigation reaches a dead-end, and learn how to creatively approach a complex problem. ${ }^{8}$ These are skills which can only be developed by learning through experience, ${ }^{9}$ which draws upon the clinical legal model that is rooted in David Kolb's cyclical learning model for reflective practice..$^{10}$ The four stages; concrete experience, reflective observations, abstract conceptualisation, and active experimentation are all part of the process that students go through on the IPL when they analyse and problem solve in what is an unstructured situation. ${ }^{11}$

\footnotetext{
${ }^{7}$ Findley, "The Pedagogy of Innocence" 1111

${ }^{8}$ Findley, "The Pedagogy of Innocence" 1109

${ }^{9}$ R. J Sternberg and L.F Zhang, eds, Perspectives in cognitive, learning and thinking styles, in Experiential Learning Theory: Previous Research and New Directions, (NJ: Lawrence Erlbaum, 2000).

${ }^{10}$ D Kolb, (2014) Experiential Learning: Experience as the Source of Learning and Development, 2nd ed, (New Jersey: Pearson Education)

${ }^{11}$ Findley, "The Pedagogy of Innocence" 1106
} 
It is unstructured because each case is unique as to the substantive and sometimes procedural law students have to research and learn, and the legal issues which go beyond the law undergraduate curriculum. ${ }^{12}$ For employees/students on the IPL, their experience as part of that learning cycle ${ }^{13}$ continually evolves depending on the subject matter of the cases that are accepted. For example, a current IPL case is one of murder, but the students had to consider a number of issues that went beyond the offence for which the client had been convicted. This included medical evidence concerning the injuries of the victim and the medical history of the client who was registered disabled, the latter had not been considered in court at all. Another case has required students to consider expert evidence which meant researching this area of law to identify how an expert is defined by the law and the parameters in which they can give evidence. The learning that derived from these issues provided a good opportunity for students to start understanding about the importance of finding and proving facts, as well as legal analysis. ${ }^{14}$ Where the students start their work after the trial and appeal have been decided, they are given a platform on which to critically reflect on how the criminal justice system has worked, and how it might work differently and more effectively. ${ }^{15}$ This also includes the limits of the court, solicitors and barristers. ${ }^{16}$

The different subject matter of the cases and their lack of obvious direction can also present a challenge to the supervision of the IPL. Unlike legal clinics which normally offer services in specific areas of law, the unpredictable nature of the subject matter makes it difficult to apply a consistent case management strategy. ${ }^{17}$ Aside from putting together timelines for the prosecution and defence which need to be done for

\footnotetext{
${ }^{12}$ Daniel S. Medwed, "Actual Innocents: Considerations in Selecting Cases for a New Innocence Project", (2003) 81 NEB. L. REV. 1097

${ }^{13} \mathrm{Kolb}$, Experiential Learning.The Kolb Learning Cycle operates in four stages; concrete experience, reflective observation, abstract conceptualisation and active experimentation

${ }^{14}$ Findley, "The Pedagogy of Innocence" 1132

${ }^{15}$ Jan Stiglitz, Justin Brooks, \& Tara Shulman, (2002) The Hurricane Meets the Paper Chase: Innocence

Projects New Emerging Role in Clinical Legal Education, 38 CAL. W. L. REV. 413

${ }^{16}$ Findley, "The Pedagogy of Innocence" 1132

${ }^{17}$ Medwed, “Actual Innocents" 1097
} 
every case, resolving any issues will depend on the offence that has been committed and the evidence that was adduced. There is however, much to draw on that provides a sound basis for the development of transferable skills which students can take with them when they graduate. ${ }^{18}$ These include: effective time management, the importance of finding and proving facts, good organisation, and exposure to the people they will come across in their professional legal careers such as supervisors, clients, barristers and solicitors. ${ }^{19}$ They also develop skills that meet the benchmark standards in law, which include, but are not limited to: the ability to recognise ambiguity and deal with uncertainty in law, the ability to communicate orally and in writing in relation to legal matters, to engage with their own personal and professional development, the ability to work collaboratively, the ability to use feedback effectively and the ability to conduct self-directed research. ${ }^{20}$

\subsection{The employer/employee environment}

Underpinning the experiential learning pedagogy, the IPL has incorporated aspects of work based learning (WBL). ${ }^{21}$ The purpose of which has been to stimulate an environment where learning is not only acquired through experience, but where it develops in response to workplace issues. ${ }^{22}$ Some of the issues students experience in the context of the legal workplace include putting together bundles under the

\footnotetext{
${ }^{18}$ Many of these skills are in the recommendations from the Legal Education and Training Review, "Setting Standards, The Future of Legal Services Education and Training in England and Wales," June 2013

${ }^{19}$ Stiglitz, Brooks, \& Shulman, "The Hurricane Meets the Paper Chase" 413

${ }^{20}$ QAA, Subject Benchmark Statement Law, Part A: Setting and maintaining academic standards, July 2015

${ }^{21} \mathrm{~J}$ Flanagan, S Baldwin and D Clarke, (2000) Works-based learning as a means of developing and assessing nursing competence, Journal of Clinical Nursing, Vol 9, 3, 360-368. See also "all and any learning that is situated in the workplace and arises directly out of workplace concerns" per Brian Stanley Lester and Carol Costley, (2010) Work-based learning at higher education level: value, practice and critique. Studies in Higher Education, 35 (5). pp 561-575

${ }_{22}$ J. Gear, A. McIntosh, \& G. Squires, (1994) Informal learning in the professions. Kingston-upon-Hull: University of Hull Department of Adult Education; M. Eraut, S. Steadman, F. Maillardet, C. Miller, A. Ali, C. Blackman, J. Furner J. \& C. Caballero (2005) Learning during the first three years of postgraduate employment. Swindon: Economic and Social Research Council (Project LINEA); M. Eraut, \& W. Hirsh, (2007) The Significance of Workplace Learning for Individuals, Groups and Organisations. Oxford: University of Oxford (SKOPE Monograph 6).
} 
constraints of time, researching areas of the law they have not yet learnt, drafting directions to experts and sorting through case files. This has been particularly effective in enabling them to engage critically and reflectively with their learning, ${ }^{23}$ whilst providing them with a sense of personal value for the input they have in the case. The elements of WBL which manifest in the project ${ }^{24}$ and will be examined in greater detail include performance related tasks such as writing reports and carrying out research; solving problems in the context of finding new evidence or a new legal argument to take to the CCRC; the employees/students learning from their work activities which can include a new aspect of substantive law (previous examples include bad character and hearsay evidence); the employees have to work as part of a team, which requires effective cooperation, patience and finding ways to work with different characters and different expertise; the enhancement of performance, where the employees are encouraged to be altruistic in the development of their skills in academic writing and referencing and the detail required for research. ${ }^{25}$ Some of these skills, whilst unique to the practice of law, do help to increase the student's employability when they graduate.

Although the learning does not take place in the offices of a law firm, the IPL office is considered by students to be akin to that space. The students understand that they are employees working for the IPL, and the skills and attitudes they develop encourage them to take responsibility for their own learning. ${ }^{26}$ This forces them to adopt a deeper approach to their learning because they become actively interested in the content of the case. ${ }^{27}$ A number of students draw upon their own experiences to understand the

\footnotetext{
23Brian Stanley Lester and Carol Costley, (2010) Work-based learning at higher education level: value, practice and critique. Studies in Higher Education, 35 (5). pp. 561-575

${ }^{24}$ E Foster, (1996) Comparable But Different: Work Based Learning for a Learning Society, WBL

Project, Final Report University of Leeds 1994-96 at pp 20-21

${ }^{25}$ JB Biggs, K Collis, (1982) Evaluating the Quality of Learning. The SOLO Taxonomy (New York:

Academic Press)

${ }^{26}$ Chapman and E Hawkins (2003) Work-based learning: making a difference in practice. Nursing Standard 17(34), 39-42

${ }^{27} \mathrm{~N}$ Entwistle, (2005) 'Contrasting perspectives on learning, in F Marton et al, eds The Experience of Learning originally published Edinburgh: Scottish Academic Press.
} 
subject matter in a way that is personally meaningful, leading to an interactive process where you can see them trying to understand ideas for themselves. ${ }^{28}$ This process also encourages the employees/students to question their assumptions about the law or legal practice, which is an important part of conceptualizing their knowledge..$^{29}$ The role of the project manager represents that of the employer in the context of facilitating learning and encouraging a more self-directed approach ${ }^{30}$ by nurturing the student's sense of responsibility. A skill which is essential to developing professional ethics. The role of the solicitor or barrister (working pro-bono with the IPL) is one of directing and mentoring the employees to undertake tasks as they would in a law firm, but which are directly relevant to the needs of the case. The use of the employer/employee relationship is a way of integrating the experience and expertise associated with WBL with the concept of learning by experience. By embedding it within a discipline context it has been effective in providing opportunities for students to develop their legal skills.

Combining theory with practice has not been without its challenges. The balance between the needs of the client and the educational requirements of the students is consistently under scrutiny. The volunteer employees/students have to prioritise their academic studies, whilst the employees/students who choose the IPL as an option have to balance their work with the other courses they have chosen. The needs of the client however, can become a competing priority, especially as the employees/students develop their knowledge and understanding of the case. Instilling professionalism through the employer/employee relationship has required careful management. The notion of the employees/students constructing identity and

\footnotetext{
${ }^{28}$ G Light, R Cox and Calkins, (2014) Learning and Teaching in Higher Education. The Reflective Professional, $2^{\text {nd }}$ ed (Sage Publications) at chapter 2

${ }^{29}$ Joseph Raelin, A Model of Work -Based Learning, Organisational Science, Vol 8, Nos. 6 (Nov-Dec 1997), 563-578 at 564

${ }^{30}$ Foster E. (1996) Comparable but Different: Work Based Learning for a Learning Society, WBL

Project, Final Report 1994-96, University of Leeds at pp20-21
} 
meaning in their work ${ }^{31}$ develops quicker in some than others, as do details such as time keeping and organisation. The project manager has to ensure that students have time to reflect on what professionalism means to them, so that they identify what they have learnt in this context. Working in small groups has and will continue to be a challenge to the students that requires consistent facilitation. As random groups ${ }^{32}$ it is inevitable that there will be behaviours which require managing in order that they do not damage the group work. The project manager as a facilitator also needs to ensure their behaviour does not damage the group work. ${ }^{33}$ This requires effective communication and reflection on how any issues should be dealt with, or could be dealt with better.

\section{Features of work-based learning}

The following features of WBL are those that form part of the pedagogy of the IPL, where self- knowledge and expertise derived from the work place are brought together alongside knowledge gained through academic study. ${ }^{34}$ This underpins the four stages of the experiential learning model.

\subsection{Performance related tasks}

The employees/students carry out tasks that could arise in legal practice, which, provide them with a particular experience to extrapolate learning from. This begins with the two-stage application process for all students who wish to work on the IPL. ${ }^{35}$ The application to work on the IPL is similar to one that could be experienced when applying for a job. In the first stage, the students are asked to write a personal statement, and investigate and write a report on an area of law that they have not been

\footnotetext{
${ }^{31}$ E Hoyle, (1995) Changing conceptions of a profession, in H. Busher and R Saran (Eds) Managing teachers and professionals in schools (London, Kogan Page)

${ }^{32}$ P Race, Making small-group teaching work, in P Race, (2006) The Lecturer's Toolkit, ( $3^{\text {rd }}$ Ed: London: Routledge)

${ }^{33}$ Race, Making small-group teaching work, in The Lecturer's Toolkit

${ }^{34} \mathrm{~J}$ Flanagan, S Baldwin and D Clarke, (2000) Work-Based Learning as a means of developing and assessing nursing competence, Journal of Clinical Nursing, 9 (3) pages 360-368 at 363

${ }^{35}$ Both students who wish to volunteer in their second and third year and students who want to choose the IPL as a third- year optional course.
} 
taught. This is used to assess writing and research skills and the ability to follow instructions, a process that is considered good practice by the Innocence Network. ${ }^{36}$ Applicants who are deemed successful at stage one against the relevant criteria ${ }^{37}$ then progress to stage two for an interview with the IPL Project Manager and Director where they also present their investigation. The previous approach had been to ask applicants to write an essay based on a set question, but this limited how well the students could articulate their own thoughts. The notion of writing a report based on having to research and investigate a point of law limits the possibility of students drafting directly from websites or articles, and demands that they have to think critically about what they are doing and how they present it. With the two-stage process, the students have to work to understand what is being asked of them, and by virtue of the two stages they demonstrate a commitment to want to be part of the project.

Other work based related tasks include writing. This normally starts with the employees/students identifying how the client was convicted of the offence(s), breaking it down into elements and showing what evidence would be required to prove each one, before moving on to how the prosecution proved the offence. When an area of interest has been identified, for instance the use of expert witnesses, the employees/students will set out the substantive law and determine how it has been applied in the case, including the necessary judicial directions. These have to provide a precise and comprehensive analysis, and they are a good exercise that proves fruitful in the development that students show over the course of the academic year.

For all cases, employees/students are required to develop a timeline for both the defence and the prosecution, separately at first, before merging them into one. This

\footnotetext{
${ }^{36}$ Justin Brooks (Californian Innocence Project) Seth Miller (Florida Innocence Project) and Joe Bodenhamer (Wrongful Conviction Project, Ohio). "Creating and Maintaining and Innocence Organisation," Innocence Network Conference, March 2017

${ }^{37}$ These include correct referencing, a good standard of academic writing and following the instructions set out for stage one.
} 
activity is normally carried out in the first 3-4 weeks because it helps to provide an understanding of the facts in the case and how the client was convicted. The employees/students have reflected on how useful the process of case management, putting together a bundle and producing the timelines has been to them, not only because they can start to understand the sheer volume of material that solicitors and barristers have to work with, but because they start to become familiar with the detail and facts of the case. Eventually the employees/students are asked to set out the history and background of the case in the format of a legal submission. This process not only enables the employees/students to use the timelines they have put together, but to cross reference them with the relevant case files, such as the defence statement, the prosecution case summary, the agreed facts etc. This will eventually be used in the application to the CCRC so they have to be written and set out clearly. This work is indicative of the standards required in legal practice, but it also balances the need for academic knowledge with professional competence. ${ }^{38}$

The project manager has the responsibility of balancing the requirements of completing these tasks to the standard required, against the employees/student's other academic studies. From experience the required 4 to 6 hours of work on the IPL can be managed alongside preparation for lectures and seminars. Evaluations indicate that students understand in some weeks they will need to work the full 6 hours or more in some instances, to ensure the required tasks are completed, yet in other weeks their tasks can be completed in less time. When, however, coursework deadlines start to loom, the employees/students have felt the pressure of the additional workload. One solution to this has been for the project manager to map out coursework deadlines for each group of employees/students and to give consideration to them when setting work. This has been proven to minimise the tension between meeting academic deadlines and fulfilling the tasks for the case. Once the employees/students meet their

\footnotetext{
${ }^{38}$ QAA (2010) Employer-responsive provision survey: A reflective report. The Quality Assurance Agency for Higher Education
} 
client, which they do shortly after completing the defence and prosecution timelines, the importance of the work they are undertaking starts to become a reality. It is at this point, that the employees/students often start to take ownership of their work and identify with what they are doing, in the context of the client being the recipient of their efforts. ${ }^{39}$ Whilst the employees/students become invigorated, the project manager needs to ensure this enthusiasm does not overtake any academic requirements from other courses. Regular meetings with each group, alongside consistent monitoring of the work being done are just two ways in which this can be achieved.

Where the Subject Benchmark Statement for Law is now predominantly skills based, these tasks directly support the employees/student's development in researching and retrieving accurate, current and relevant information from a range of sources, alongside their ability to communicate in writing. ${ }^{40}$ Tasks directed by the solicitor or barrister have involved drafting directions to an expert to review evidence and putting together bundles containing the evidence to be reviewed. The employees/students have had to research the experts they wish to approach to conduct the review pro bono, by identifying individuals whose field of expertise is most relevant to the evidence to be reviewed. This process has exposed the employees/students to understanding how to identify gaps in their own knowledge and subsequently acquire new knowledge, a skill which is highlighted in the Subject Benchmark Statement for Law. ${ }^{41}$

\footnotetext{
${ }^{39}$ S Chandler and P Robotham (2006), Extending the Comfort Zones: Loosening the Clinical Straight Jacket, International Journal of Clinical Legal Education Conference. London Institute of Advanced Legal Studies

40 Subject Benchmark Statement, Law, July 2015

http://www.qaa.ac.uk/en/Publications/Documents/SBS-Law-15.pdf

${ }^{41}$ Subject Benchmark Statement Law, July 2015

http://www.qaa.ac.uk/en/Publications/Documents/SBS-Law-15.pdf
} 


\subsection{Solving Problems}

Problem-solving requires the employees/students to actively experiment with their knowledge. They need to work together and co-operate with each other embracing the different skills and expertise each have, which, in turn leads to new skills being developed and shared expertise. ${ }^{42}$ The regular meetings between the teams of employee/students helps everyone to participate in joint problem solving. The problem at the forefront of the learning process is the substance of the application to the CCRC. In much the same way as problem- based learning the knowledge and skills are acquired, rather than communicated. ${ }^{43}$ The employees/students have to find, frame and analyse the issues themselves, enabling self-directed learning and the time to understand the material more deeply. ${ }^{44}$

Initially the employees/students are often faced with smaller problems such as a mass of case files, much of which they have never seen before. If they are lucky the files are ordered and indexed, but more often than not they arrive in disarray. This requires them to go through every document and ascertain what they have and then index it for the purpose of the IPL case management system. At the same time, the solicitor or barrister working pro bono on the case may require them to produce a bundle of all the essential documents. This begins the development of organisation and time management, which is an important lesson for their legal careers. Their academic lives are scheduled around lectures and seminars and dates for final exams, but legal practice is not so neatly arranged. As a solicitor or barrister, they could start the week expecting to work on one case, but end up not opening that file because of a new client or emergency in an existing case. ${ }^{45}$

\footnotetext{
${ }^{42} \mathrm{~J}$ Flanagan, S Baldwin and D Clarke, (2000) Work-Based Learning as a means of developing and assessing nursing competence, Journal of Clinical Nursing, 9 (3) pp 360-368 at 364

${ }^{43}$ R Batty, (2013) Well There's Your Problem- The Case for Using PBL to Teach Law to Business Students, 47 Law Teacher, 243

${ }^{44} \mathrm{~J}$ Macfarlane and J Manwaring, (1998) Using Problem-Based Learning to Teach First Year Contracts 16 Journal of Professional Legal Education, pp 271-298 at 272-274

${ }^{45}$ Stiglitz, Brooks, \& Shulman, "The Hurricane Meets the Paper Chase" 413
} 
It is during the process of problem-solving that the employees/students experiment using their conceptual knowledge. Theory-based classroom experiences sometimes present solving problems as neat packages. ${ }^{46}$ The reality of case work on the IPL removes this impression. The knowledge invariably has to be modified in order to adapt it to the specific problem they face, meaning that the employees/students have to change their approach in mid-stream, negotiate and think independently. ${ }^{47}$ Many cases do not follow an obvious trajectory, ${ }^{48}$ so the problems can range in their complexity depending on the facts of the case, the evidence adduced at trial and the judicial directions required for the jury. The students have to consider how the law has been applied and whether it was done so correctly, and whether it could be applied differently. Thus, the relationship between academic theory and the practice of law can be demonstrated. Previous thinking outside the box has included drafting a new legal argument concerning eye -witness identification based on the use of the Turnball judicial directions. ${ }^{49}$ Another example has been identifying what to ask an expert in order to rule out the possible circumstances in which a body could end up in a well almost upright, with no signs from the post-mortem of it having been lowered using a rope.

\subsection{Learning from work activities/Reflective practice}

The process of reviewing transcripts, police reports, witness statements and talking to the client requires students to impose their critical judgement on what they are reviewing and to form a plan as to how best to solve the issues. It is through these activities that the employees/students conceptualise their knowledge. These activities all encourage the employees/students to work autonomously, and to take

\footnotetext{
${ }^{46}$ Joseph Raelin, A Model of Work -Based Learning, Organisational Science, Vol 8, Nos. 6 (Nov-Dec 1997), 563-578 at 566

${ }^{47}$ Raelin, "A Model of Work -Based Learning" 566

${ }_{48}$ Medwed, "Actual Innocents" 1035

${ }^{49}$ Turnbull [1977] QB 224, where the case against an accused depends wholly or substantially on the correctness of one or more identifications of the accused - which the defence alleges to be mistaken the judge should warn the jury of the special need for caution before convicting the accused in reliance on the correctness of the identification.
} 
responsibility for their learning which can take place without direct instruction. They manage their own learning in the context that together the employees/students develop confidence to ask questions in order to understand what they need to do. By adopting the approach of an employer within an academic course, it has created a safe learning environment which encourages the development of students as independent learners.

The activity that produces a significant amount of learning for the employees/students is visiting their client in prison, seeing first -hand the security procedures and the environment that they live in. They start to empathise with the impact that being in custody can have on an individual, whilst at the same time they begin to understand the significance of their work. These visits are often done at the start of the case, but not until they have understood the facts as presented in the case files. This is because of the need to ask the client questions about facts that don't make sense, or to ask for information that is missing and this cannot be done without having a sufficient understanding of the case. The employees/students are expected to come up with questions they would like the client to answer on the legal visit. The students undertake training with the project manager and their solicitor or barrister on the use of open questions, how to approach sensitive questions and how to phrase a question. During the visit the employees/students are encouraged to lead the questioning but they are supported either by the project manager or the lawyer who accompanies them. A note of the meeting is circulated to the other team members which is then used to reflect on the answers given by the client. It is at this point that the employees/students often start to conceptualise their theories as well as consider new questions.

Whilst only those students who choose the IPL as an option in their final year are assessed in terms of passing the course, all employees/students are encouraged to reflect on what they have learnt. The use of work-based learning can only be successful if the work environment supports the process of reflection, and encourages 
the employees/students to understand and respond to their own learning. ${ }^{50}$ Reflection is the thread that draws together both the volunteers and option employees/students.

The activities undertaken as part of working on a case can be described as formative where they aid development, improvement and learning. The means of summative assessment are a portfolio of work and an extended essay, the topic of which can be connected to the case the employees/students have been working on or on an issue connected to wrongful convictions or miscarriages of justice. The scope is intentionally broad, to allow for a range of choice and variety. These means of assessment offer an opportunity for employees/students to not only use the skills developed whilst working on the IPL, but to also identify them. This helps them to realise their own learning and then articulate this for future employment.

The extended essay provides a platform to demonstrate some of the key skills that have been developed whilst working on the IPL, that of research, identifying an issue or question that needs answering, academic writing to a good standard, accurate referencing, and the ability to set out complex issues clearly and concisely. The ability of the employees/students to choose what they write about is important for them as independent learners and their engagement with the subject matter.

Over the years, it has become evident that the portfolio underpins the pedagogy of the IPL, providing respect for individual differences and the varied contexts in which people work. ${ }^{51}$ The portfolio allows for the employees/students to showcase the work they have done on the IPL, for example research into the offence, directions to an expert, a comparison of medical reports, the defence and prosecution timeline. This list is not exhaustive. ${ }^{52}$ The notion that the employees/students can build up a picture

\footnotetext{
${ }^{50}$ Greg Light, Roy Cox, Susanna Calkins, (2014) Learning and Teaching in Higher Education. The Reflective Professional, 2nd Ed (Sage: London) p226

${ }^{51}$ Greg Light, Roy Cox, Susanna Calkins, (2014) Learning and Teaching in Higher Education. The Reflective Professional, 2 ${ }^{\text {nd }}$ Ed (Sage: London) p220

${ }^{52}$ C P White (2004) Student portfolios: an alternative way of encouraging and evaluating student learning, New Directions for Teaching and Learning, 100, pp 37-42
} 
of their experience on the IPL, underpins their learning through practice and the sense of responsibility they have shaped towards that learning. ${ }^{53}$ In the same way they are encouraged to take ownership of the case they work on, they have to take responsibility for what they include in their portfolio.

Reflecting on an experience can be complex and is a skill that also needs to be developed. On the IPL, it is undertaken in group discussions, often as part of the regular meeting where the employees/students are asked to identify what they learnt through a recent activity and what they have learnt about themselves whilst carrying out that activity. In addition, workshops also support the development of writing in a reflective rather than descriptive manner. Employees/students are provided with an opportunity to discuss feedback given in response to a particular task or piece of work and to reflect on their learning. They are asked to answer the following questions concerning that feedback:

1) How did it make you feel when you received this feedback?

2) Did you understand why this piece of feedback had been given to you?

3) Did you understand how to use this piece of feedback and if no did you ask questions in order to understand?

4) Have you been able to use this piece of feedback since it was given to you in other work or tasks you have done?

The employees/students are put into pairs with someone who they do not work with, and they are asked to tell each other the feedback they received, and then discuss it using the five questions. The project manager listens to what is being said between each employee/student and joins in the discussion where relevant. The employees/students are then brought back into a larger group discussion where they are asked to think about the exercise that has just taken place and what they learnt

\footnotetext{
${ }^{53}$ R Cox (1996) Teaching. Learning and assessment in higher education, Anthropology in Action 3(2)
} 
from it. At this point the employees/students realise that feedback can evoke feelings of disappointment that their work was not up to the standard required, that understanding how to use the feedback in other tasks or work requires some thought, and that not questioning feedback in order to understand it is common.

The employees/students then return to work in their pairs and interrogate the task that led to the feedback in order to probe a deeper level of reflection. ${ }^{54}$ In reflecting about the event, the employees/students are asked to think about the 'else factor'. ${ }^{5}$ This helps the students move away from simply describing the task and to expand on what happened, encouraging a deeper awareness of not only their own learning, but also the learning about themselves reflecting about how they have become able to demonstrate evidence of their own achievement. ${ }^{56}$ For example, an employee/student who was given feedback from the task of putting together a bundle for their pro-bono solicitor would think about what else was going on at the time they carried out that task, what else happened when they carried out that task, and how else could they achieve that work. By answering these questions, the employee/student starts to understand how external influences can affect their work, whether they fully understood what they needed to do when putting the bundle together and whether they were giving their full attention to the task, and what, if anything they would do differently.

\subsection{Work teams ${ }^{57}$}

Working closely with other people in any environment requires skill, and the employees/students on the IPL are fortunate enough to have the opportunity to learn those skills before they leave university. It is also where the process of reflection can support group, as well as individual learning. ${ }^{58}$ Being exposed to working in a small

\footnotetext{
${ }^{54}$ P Race, (2010) Making Learning Happen $2^{\text {nd }}$ Ed (Sage: London) at 224-225

55 Race Making Learning Happen at 225

${ }^{56}$ Race Making Learning Happen at 225

${ }^{57}$ Medwed, "Actual Innocents" 1148, "work teams" are a fixture of legal practice

${ }^{58}$ Raelin, "A Model of Work -Based Learning" 568
} 
group with students they may not know has sometimes been more of a challenge than learning the law. Learning how to be patient with someone who takes longer to read a document and think about its contents can take time and does not come easily for some. Working together to achieve the same goal, especially when under time constraints requires flexibility and cooperation. Students are exposed to this on their legal skills course where they often collaborate outside of the classroom to get work finished. In an employer environment however, they may not get the luxury of being able to finish the work outside of the work place, where more often than not, the work will be time dependent. By exposing the employees/students to different characters that they have to work closely with, they become aware of how they work in a group and also how they manage themselves in a group. ${ }^{59}$ The process of working in a small group does not however, always run smoothly. The most common factors that have affected small-group working include employees/students not doing their part to prepare for group meetings, balancing dominant learners with passive learners in the group, and the project manager achieving a balance in the learning experience across all participants in the group. ${ }^{60}$

Where employees/students have not prepared for a group meeting, the allocation of individual actions has been successful in overcoming this issue. This allows for the learning outcomes to be clearly set out so the employee/student knows what they need to do, and what they should produce for a particular task. The option of leaving it to someone else to do is not available. This approach encourages a greater degree of involvement and also enables the project manager to remind the group of the benefit of equal participation. ${ }^{61}$ On the occasion where employees/students have continued not to prepare, the reason has been unconnected to their learning on the IPL leading to other support being instigated. Giving individual and group actions also helps

\footnotetext{
59J. Moon, Making Groups Work, HEA, Subject Centre for ESCalate. (2009) Available at https://www.plymouth.ac.uk/uploads/production/document/path/2/2418/Making groups work.pdf ${ }^{60}$ P Race, (2010) Making Learning Happen $2^{\text {nd }}$ Ed (Sage: London) at 174

${ }^{61}$ P Race, (2006) The Lecturer's Toolkit (Routledge: London) per Chapter 4
} 
support those employees/students who are passive in the group environment and do not want to risk being more involved in case what they suggest or do is wrong. ${ }^{62} \mathrm{By}$ giving them ownership of a particular piece of work or task, they have an opportunity to demonstrate their development alongside supporting the group. Where there is a dominant personality or personalities in a group, the process of getting all the employees/students to reflect on how the group is working, who took the lead, who spoke to most, and whether everyone agreed with the ideas being put forward, can highlight that this element exists. It can cause the dominant individual to reflect on their assertive behaviour, but also lead to the other group members recognising assertive behaviour and subsequently reducing the opportunity for one person to dominate for too long. ${ }^{63}$

Whilst small group work has been criticised as resource intensive, ${ }^{64}$ in the IPL context it has worked well despite the need for consistent facilitation. Just as employee/student behaviour can damage group work so can the behaviour of the project manager. Preparing adequately for a group meeting is essential in ensuring that the group feels their work is being taken seriously. ${ }^{65}$ Keeping adequate records of the meetings and the relevant actions also helps to support each group. There is a fine balance between being too controlling over the employees/students work and ensuring the actions have been completed. It can be more beneficial to help the group work productively towards their goals rather than specify how they have to reach them. Some groups have required more support than others in the process of working together, but every group on the IPL has gone through the storming phase. ${ }^{66}$ The storming phase can occur at any time during the life of the group and some groups

\footnotetext{
${ }^{62}$ Race, The Lecturer's Toolkit

${ }^{63}$ Race, The Lecturer's Toolkit

${ }^{64} \mathrm{~K}$ Heycox, N Bolzan, Applying problem based learning in first year social work, in D Boud, G Feletti, eds, The Challenge of problem-based learning, (London: Kogan Page, 1991)

65 Race, The Lecturer's Toolkit

${ }^{66}$ BW Tuckman (1965) 'Development sequence in small groups' Psychological Bulletin, 63: 384-99 (reprinted in 2001 in Group Facilitation: A Research and Applications Journal, 3:66-81)
} 
experience only a mild version. ${ }^{67}$ The hostility in one group did lead to it breaking down. Fortunately this was towards the end of the academic year and the employees/students were in their final year, so the conflict ended when they graduated. The issues manifested from external influences concerning the friendship of two of the group members. As a result regular group reflection as described above, was introduced alongside regular informal discussions with individual group members, which has prevented such a situation from arising again. Equalising any small group requires a consistent approach and a degree of commitment, which can be time consuming. ${ }^{68} \mathrm{It}$ is, however, an entirely worthwhile exercise when the students begin to realise their potential, and start to perform in the context of constructive activity and function maturely and productively. ${ }^{69}$

The facilitation of the small groups on the IPL is one of ongoing refection into what works and what does not. It is unrealistic to think that changes could not be made in the future, depending on the cases being worked on and the employees/students that are working on them.

\subsection{Enhancing performance}

The employees/students are encouraged to be altruistic with the skills that they develop whilst working on the IPL, and actively use them on their other courses, whether that is in the second year or final year of their law degrees. This will only work however, if the employers/students are motivated to learn from the experiences that they have engaged with. ${ }^{70}$ They also need to learn within their own capability in

\footnotetext{
${ }^{67}$ Greg Light, Roy Cox, Susanna Calkins, (2014) Learning and Teaching in Higher Education. The Reflective Professional, $2^{\text {nd }}$ Ed (Sage: London) p36

${ }^{68}$ C. Lantz, (2009) Working with small groups, Higher Education Academy Psychology Network ${ }^{69}$ BW Tuckman (1965) 'Development sequence in small groups' Psychological Bulletin, 63: 384-99 (reprinted in 2001 in Group Facilitation: A Research and Applications Journal, 3:66-81)

${ }^{70}$ P. Askham, (1997) Workplace learning: removing the barriers. In Flexible Learning in Action, Case Studies in Higher Education in eds Hudson R, A Maslin-Prothero and L Oates, (Guildford: Kogan Page Ltd) pp 67-72
} 
order for the experience to be positive and effective. ${ }^{71}$ The activities on the IPL are geared towards achieving this. In particular, the number of corrections in reports greatly reduce because students understand the standard of work that is required of them and they strive to meet those standards. The amount of direction required for them to research areas of the law reduces because the employees/students have developed the skills to identify the research themselves. The confidence to ask questions in order to get clarity increases because they know that without doing so, they won't be able to proceed quickly and effectively. The ability of the employees/students to critically reflect on how to use the law against the facts of a case also greatly improves. The skills they have developed in legal writing, drafting, referencing, research and so on, can be used for all their courses on an undergraduate law degree as well as for their future employer.

Every aspect of the work the employees/students undertake on the IPL helps to instil aspects of professionalism. Work based learning has been found to be an effective vehicle for personal and professional growth ${ }^{72}$ and certainly that is evident from the pedagogy employed here. Evaluations of the IPL suggest that the employees/students have developed an increased confidence in areas such as public speaking, speaking in meetings, the ability to take on greater responsibility, and their ability to produce a good standard or written work and research. A number of employees/students have also suggested that they have an increased belief in themselves which has led to them having the confidence to challenge their own views. The employees/students have also highlighted their improved time management as a common area in which they have changed their way of working or studying for the better, making better and more effective use of their time. Everyone who has worked on the IPL has actively realised they are not only are able to reflect upon what they have learnt and find evidence of

\footnotetext{
${ }^{71}$ G Gibbs, (1992) Improving the Quality of Student Learning, Development of Adult Education, UDACE London

${ }^{72}$ Brian Stanley Lester and Carol Costley (2010) Work-based learning at higher education level: value, practice and critique. Studies in Higher Education, 35 (5). pp. 561-575 at 567
} 
that learning, but can also identify how they have used that learning in others areas of the academic or personal lives. Some have realised this has happened unconsciously, whilst others have made a conscious effort to put into practice the feedback they have received. This demonstrates not only the positive response to the pedagogy, but also the impact that the employer/employee environment has had on law students in preparing them to become independent professionals.

\section{Conclusion}

The combination of experiential learning and elements of WBL has produced a positive employer/employee environment. The unique starting point for the learning cycle, at the end of the criminal justice process enables the employees/students to critically reflect not only on what has been done, but what could have been done better. The conscious decision to start the employer/employee relationship with the application process indicates the standard expected from those who work on the project. This is borne out in the development the students show throughout the year because of how they engage with the work on the project. The skills they develop, whilst they meet some of the subject benchmark standards are not only academic. The ability to communicate orally and in writing, to self-manage a workload and to develop personally and professionally are also life skills. The significant learning opportunities include visiting the client in prison and seeing the impact that being in custody can have. To then be able to interview the client and reflect on how their answers impact on the investigation into the case provides an experience that the undergraduate curriculum cannot give. The incorporation of reflecting on the skills and experience support the prospect of translating the learning into legal practice as well as others areas of work.

The learning is not only for the employee/students working on the project. The project manager consistently reflects on what has worked and what could be improved. The different subject matter of the cases and the evolution of employees/students provides an opportunity to build on the existing foundations and to modify them where 
necessary. The challenges posed by this pedagogy are outweighed by working with dedicated and enthusiastic employees/students.

Whilst the elements of WBL are not used in a physical workplace environment, this does not distract from the way they manifest in the learning on the project, which has had a positive effect on the employees/students overall. Their feedback has included an increased confidence to ask questions, the confidence to speak to lawyers, having developed better analytical skills and attention to detail, working confidently as part of a team and developing client interviewing skills. The employees/students leave the IPL, and where third-year students are concerned leave the university, with a better understanding of how "the law is applied in real life,"73 in addition to having had a "unique and rewarding experience.". ${ }^{74}$

\footnotetext{
${ }^{73}$ As provided in feedback by a $3^{\text {rd }}$ year LLB student and Student Case Worker Innocence Project London 2016-2017

${ }^{74}$ As provided in feedback by a $3^{\text {rd }}$ year LLB student and Student Case Worker Innocence Project London 2016-2017
} 